\title{
Abdominal bloating is the most bothersome symptom in irritable bowel syndrome with constipation (IBS-C): a large population-based Internet survey in Japan
}

\author{
Motoyori Kanazawa ${ }^{1 *}$, Hiroto Miwa², Ayako Nakagawa ${ }^{3}$, Masanori Kosako ${ }^{3}$, Hiraku Akiho ${ }^{3}$ and Shin Fukudo ${ }^{1}$
}

\begin{abstract}
Background: Abdominal bloating is a common symptom in patients with irritable bowel syndrome with constipation (IBS-C). However, it is not included among the required items in the Rome III diagnostic criteria for IBS. Little is known about an impact of abdominal bloating seen in patients with IBS-C. Using a large population-based sample, the aim of the present study was to investigate what is the most bothersome symptom in subjects with IBS-C.

Methods: An Internet survey of 30,000 adults drawn from the general public throughout Japan was conducted to identify subtypes of IBS using the Rome III diagnostic questionnaire. Consecutively, the screened subjects with IBS-C and the same number of age- and sex-matched non-IBS subjects who were randomly selected as controls were asked to answer a questionnaire on the degree of anxiety they experienced in their daily lives, thoughts about bowel habit, and their dominant gastrointestinal symptoms together with exacerbation factors (for IBS-C only).

Results: The screening survey showed that the prevalence of overall IBS was $16.5 \%$ (female $17.4 \%$, male 15. $5 \%$ ) and that $2.8 \%$ met the criteria for IBS-C, $4.5 \%$ for IBS with diarrhea (IBS-D) and $8.2 \%$ for mixed IBS (IBS-M). Seven hundred and fifty-nine of 835 (90.9\%) subjects with IBS-C and 746 of 830 (89.9\%) control subjects completed the consecutive questionnaire. IBS-C subjects felt a higher degree of anxiety in their daily lives $(p<0.01)$ and considered bowel habit to be an indicator of health $(p<0.01)$ to a greater extent than control subjects. In IBS-C, the degree of anxiety was significantly associated with abdominal discomfort $(p<0.01)$, pain $(p<0.01)$ and bloating $(p=0.02)$, but not with the frequency of bowel habit $(p>0.1)$. Abdominal bloating was the most bothersome symptom $(27.5 \%)$, which was more likely to occur after a meal (52.2\%), at work/school (29.2\%) and during times of stress (26.8\%). Only $4.5 \%$ of IBS-C subjects reported abdominal pain as the 'most bothersome' symptom.
\end{abstract}

Conclusions: A large population-based Internet survey suggests that abdominal bloating has a great impact on the daily lives of subjects diagnosed with IBS-C. Not only bowel movement/abdominal pain but also abdominal bloating should be evaluated in patients with IBS-C.

Keywords: Irritable bowel syndrome (IBS), Constipation, Abdominal bloating, Stress, Food, Epidemiology

\footnotetext{
* Correspondence: m-kanazawa@med.tohoku.ac.jp

'Department of Behavioral Medicine, Tohoku University Graduate School of

Medicine, 2-1 Seiryo, Aoba, Sendai 980-8575, Japan

Full list of author information is available at the end of the article
} 


\section{Background}

Irritable bowel syndrome (IBS) is a common functional gastrointestinal (GI) disorder that affects between 10 and $20 \%$ of the population worldwide [1]. Based on the Rome III diagnostic criteria for functional GI disorders, IBS is defined as recurrent abdominal pain or discomfort (at least 3 days per month in the last 3 months) associated with at least two of the following: improvement with defecation, onset associated with a change in stool frequency, and/or onset associated with change in stool form [2]. The diagnosis of IBS is subtyped by the predominant stool pattern: constipation (IBS-C), diarrhea (IBS-D), mixed (IBS-M), or unspecified (IBS-U) [2].

Approximately two-thirds of subjects with IBS relate their symptoms to their intake of food [3, 4]. Most of IBS patients modify their diet, and these modifications sometimes result in an inadequate diet [3] which may be associated with bowel symptoms. Patients with IBS also feel more stress compared to healthy subjects in their daily life $[5,6]$. IBS symptoms often exaggerate when patients feel stress and/or anxiety [7]. Moreover, it has been reported that menstruation was associated with a worsening of abdominal pain and bloating and with more increase in rectal pain sensitivity compared with most other phases of the menstrual cycle in patients with IBS [8].

Abdominal bloating is commonly reported by patients with IBS [9]. However, it is not included among the required items in the Rome III diagnostic criteria [2]. Patients with IBS-C show more abdominal bloating and/ or distention than those with IBS-D [10]. Constipation is often associated with delayed gastrointestinal transit [11]. The severity of abdominal bloating correlated strongly with the degree of abdominal distention only in IBS-C [12], suggesting that the pathophysiology is likely to be different between subtypes of bowel habit.

In general population, we have found that even non-consulters with IBS showed more impaired quality of life (QOL) compared to non-IBS subjects as well as patients with IBS $[6,13]$. It has been reported that IBS symptom severity was associated with lower QOL [14, 15]. However, little is known about an impact of IBS symptoms including abdominal bloating seen in patients with IBS-C. Using a large populationbased sample, the aim of the present study was to investigate what is the most bothersome symptom in subjects with IBS-C.

\section{Methods}

As a preliminary survey, an Internet survey of 30,000 adults drawn from the general public throughout Japan (that is, from 47 prefectures in Japan) was conducted to identify subtypes of IBS. Participants were required to meet the following criteria to be eligible for the survey:
(1) no conflicts of interest with advertising, marketing research, health care, or pharmaceutical/chemical companies; (2) 20-79 years of age; and (3) subjects who understand Japanese and were living in Japan. They were randomly selected using an online survey system (Automatic Internet Research System: AIRs, Macromill, Inc., Japan). Same numbers of males and females from the different five aged groups (20s, 30s, 40s, 50s and 60-79 years; 3000 subjects each) registered with the Macromill monitor panel (Macromill, Inc., Japan) were recruited during October 28-31, 2013 (Table 1).

Table 1 Demographics of study subjects (Preliminary study)

\begin{tabular}{|c|c|}
\hline & $\begin{array}{l}\text { Participants } \\
(n=30,000), n(\%)\end{array}$ \\
\hline \multicolumn{2}{|l|}{ Gender and age range (years) } \\
\hline 20-29 in females & $3000(10)$ \\
\hline 20-29 in males & $3000(10)$ \\
\hline 30-39 in females & $3000(10)$ \\
\hline 30-39 in males & $3000(10)$ \\
\hline 40-49 in females & $3000(10)$ \\
\hline $40-49$ in males & $3000(10)$ \\
\hline $50-59$ in females & $3000(10)$ \\
\hline $50-59$ in males & $3000(10)$ \\
\hline 60-79 in females & $3000(10)$ \\
\hline $60-79$ in males & $3000(10)$ \\
\hline \multicolumn{2}{|l|}{ Marital status } \\
\hline Married & $17,391(58)$ \\
\hline Not married & $12,609(42)$ \\
\hline \multicolumn{2}{|l|}{ Annual household income (yen) } \\
\hline$<2$ million & $2557(8.5)$ \\
\hline 2-4 million & $6818(22.7)$ \\
\hline 4-6 million & $6564(21.9)$ \\
\hline 6-8 million & $3940(13.1)$ \\
\hline 8-10 million & $2321(7.7)$ \\
\hline 10-12 million & 1089 (3.6) \\
\hline 12-15 million & $691(2.3)$ \\
\hline 15-20 million & $300(1.0)$ \\
\hline$\geqq 20$ million & $146(0.5)$ \\
\hline unknown & $2795(9.3)$ \\
\hline not answered & $2779(9.3)$ \\
\hline \multicolumn{2}{|l|}{ Diagnosis of IBS } \\
\hline non-IBS & $25,058(83.5)$ \\
\hline IBS (overall) & $4942(16.5)$ \\
\hline IBS with constipation (IBS-C) & $835(2.8)$ \\
\hline IBS with diarrhea (IBS-D) & $1359(4.5)$ \\
\hline Mixed IBS (IBS-M) & $2452(8.2)$ \\
\hline Unspecified IBS (IBS-U) & $296(1.0)$ \\
\hline
\end{tabular}


The IBS module on the Japanese version of the Rome III diagnostic questionnaire of which the validity and reliability have already been confirmed $[16,17]$ was used to identify IBS and subtypes of bowel habit (Additional file 1: Figure S1). IBS-C was defined when a patient reported hard or lumpy stools $\geq 25 \%$ of the time, and loose or watery stools $<25 \%$ of the time, IBS-D was defined when a patient reported loose or watery stools $\geq 25 \%$ of the time, and hard or lumpy stools $<25 \%$ of the time, IBS-M was defined when the patient reported loose or watery stools $\geq 25 \%$ of the time, and hard or lumpy stools $\geq 25 \%$ of the time, and IBS-U was defined when the patient could not be subtyped according to these criteria, but met all other diagnostic criteria for IBS [2]. Additionally, frequency of abdominal bloating/distention in the last 3 months was also asked. The online system guided participants to complete the questionnaire without remaining missing item answers.

Consequently, of the 30,000 participants, the screened subjects diagnosed as IBS-C and the same number of age- and sex-matched non-IBS subjects who were randomly selected as controls were invited to a main survey during November 1-4, 2013.

In the main survey, IBS-C subjects and controls were asked to answer a questionnaire which consists of 7 items on the degree of anxiety they experienced in their daily lives, number of bowel movement in a week and thoughts about bowel habit, and 6 items on their dominant GI symptoms (from the first to the third place) together with exacerbation factors such as situations and time periods in their daily lives (for IBS-C only, Additional file 2: Figure S2).

We conducted an anonymous Internet survey but regarded the online response as obtained informed consent for the present study. The disclosure of this study was approved by the Ethics Committee of Tohoku University School of Medicine (approval number: 2015-1-405).

The Mann-Whitney $U$-test or $\chi^{2}$ test was used for comparisons between two groups. The Kendall's t-b was used to evaluate associations between the symptoms and exacerbation factors among IBS-C. The level of statistical significance was set at a $P$-value of less than 0.05 .

\section{Results}

\section{The preliminary survey}

The demographics of 30,000 participants were shown in Table 1. Mean age with standard deviation (SD) of the participants was $45 \pm 14$ years. The screening survey showed that the prevalence of overall IBS was $16.5 \%$ (female $17.4 \%$, male $15.5 \%$ ) and that $2.8 \%$ met the criteria for IBS-C, $4.5 \%$ for IBS-D, $8.2 \%$ for IBS-M, and $1.0 \%$ for IBS-U. Subjects with IBS $(n=4942)$ were more likely to be female (53.0 vs. $49.4 \%, p<0.01$ ) and were younger ( $42 \pm 14$ vs. $45 \pm 15$ years, $p<0.01)$ compared to
non-IBS subjects $(n=25,058)$. IBS-C subjects alone $(n=835)$ were much more likely to be female (72.2 vs. $49.4 \%, p<0.01)$ but were older $(47 \pm 14$ vs. $45 \pm 15$ years, $p<0.01)$ compared to non-IBS subjects. There was no significant difference in annual household income between IBS and non-IBS subjects. Subjects with IBS (overall, 70.0 \%; IBS-C, $84.2 \%$; IBS-D, 53.3 \%; IBS-M, 76.6 \%; IBSU, $51.7 \%$ ) were more likely to report abdominal bloating for at least two to three days a month compared to nonIBS subjects $(19.5 \%, p<0.01$, respectively).

\section{The main survey}

Seven hundred and fifty-nine of 835 (90.9 \%, 541 females) subjects with IBS-C and 746 of 830 (89.9\%, 537 females) age- and sex-matched subjects with non-IBS (controls) completed the consecutive questionnaire. IBS-C subjects felt a higher degree of anxiety in their daily lives $(p<0.01)$ and considered bowel habit to be an indicator of health $(p<0.01)$ to a greater extent than control subjects (Table 2).

The most common symptom associated with constipation in subjects with IBS-C was abdominal bloating $(80.1 \%)$ and was followed by excessive gas $(71.3 \%)$ and abdominal discomfort (64.3\%), whereas $29.1 \%$ of IBS-C subjects reported abdominal pain during constipation (Table 3). The degree of anxiety was significantly associated with abdominal discomfort (Kendall's $\tau=0.09, p<0.01$ ), pain $(\tau=0.11, p<0.01)$, and bloating $(\tau=0.08, p=0.02)$, but not with the frequency of bowel habit $(\tau=-0.04, p>0.1$, Table 3).

As shown in Fig. 1 and Table 4, the most bothersome symptom in subjects with IBS-C was abdominal bloating (27.5\%, 163 females and 46 males), which was more likely to occur after a meal (52.2\%), at work/school (29.2 \%), during times of stress (26.8 \%) and during menstruation ( $11.7 \%$, females only). Only $4.5 \%$ of IBS$\mathrm{C}$ subjects (25 females and 9 males) reported abdominal pain as the most bothersome symptom, which was more likely to occur after a meal (26.5\%), at work/school (29.4\%), during times of stress (29.4\%) and during menstruation ( $48.0 \%$, females only). IBS-C subjects were more likely to report that the bothersome symptoms usually occur throughout the day or during a nonspecific period of time rather than at a regular time during the day (data were not shown).

\section{Discussion}

We conducted a large-scale Internet survey investigating 30,000 adults from the general public throughout Japan. In this study, we estimated frequencies of the subtypes of IBS using the Rome III diagnostic questionnaire [16, 17], and then investigated what is the most bothersome symptom and what factors in the daily life exaggerate the dominant symptoms among subjects with IBS-C. As long 
Table 2 Comparisons of beliefs about bowel habit between IBS-C and controls (Main study)

\begin{tabular}{|c|c|c|c|}
\hline & Controls $(n=746), n(\%)$ & IBS-C $(n=759), n(\%)$ & $p$-value \\
\hline Female/male number & $537 / 209(72.0 / 28.0)$ & $541 / 218(71.3 / 28.7)$ & n.s. \\
\hline Age (mean $\pm S D$, years) & $47 \pm 14$ & $47 \pm 14$ & n.s. \\
\hline Frequency of bowel habit (median, times/week) & 7 & 3 & $<0.01$ \\
\hline Ideal frequency of bowel habit & & & $<0.01$ \\
\hline 6 times/week or less & $113(15.1)$ & $165(21.7)$ & \\
\hline 7 times/week & $581(77.9)$ & $563(74.2)$ & \\
\hline 8 times/week or more & $52(7.0)$ & $31(4.1)$ & \\
\hline Considered bowel habit to be an indicator of health & & & $<0.01$ \\
\hline None & $291(39.0)$ & $71(9.4)$ & \\
\hline Sometimes & $206(27.6)$ & $221(29.1)$ & \\
\hline Often & $90(12.1)$ & $186(24.5)$ & \\
\hline Mostly & $69(9.2)$ & $148(19.5)$ & \\
\hline Always & $90(12.1)$ & $133(17.5)$ & \\
\hline Degree of anxiety in daily life & & & $<0.01$ \\
\hline None & $403(54.0)$ & $176(23.2)$ & \\
\hline Sometimes & $283(37.9)$ & 440 (58.0) & \\
\hline Often & $46(6.2)$ & $111(14.6)$ & \\
\hline Almost & $14(1.9)$ & $32(4.2)$ & \\
\hline
\end{tabular}

as we know, this is the first report on a large number of subjects diagnosed as IBS-C demonstrating that the degree of anxiety in their daily lives is not always associated with frequency of bowel movement. Furthermore, we also found that the most bothersome symptom, abdominal bloating, occurs most often after meal, subsequently at work or school and during time of stress in subjects with IBS-C.

The sensation of abdominal bloating may affect 10 to $30 \%$ of healthy subjects and up to $96 \%$ of patients with IBS [9]. Abdominal bloating is more often noted by females with IBS than males, with symptoms increasing in relation to menses [18]. Abdominal bloating is associated with decreased QOL and may cause a higher number of physician visits [19]. Indeed, the IBS symptom severity scale (IBS-SSS) [20], which is widely used to assess the severity of IBS, consists of the item on the severity score for abdominal bloating as well as abdominal pain. However, the presence of abdominal bloating in other functional GI disorders and even in healthy subjects [19] means that it is not necessarily considered a diagnostic criterion for IBS.

'Abdominal bloating' is not always a specific term that implies both to the subjective sensation and to the objective or 'visible' abdominal distention [21]. In the present study, the symptom descriptions in Japanese, 'abdominal bloating', 'abdominal distention', 'sensation of excessive gas', 'tightness in the abdomen' and 'abdominal fullness' were used as independent symptomatic items on the main questionnaire. In our findings, the most common symptom of these 5 terms which IBS subjects expressed during constipation was abdominal bloating and the fewest was abdominal fullness (see Table 3 ).

Previous findings of abdominal girth using plethysmography [21, 22] may support our results of different frequencies of abdominal bloating and distention in subjects with IBS-C. Using this technique it has been demonstrated that most patients who have abdominal distention also report abdominal bloating and that patients with bloating alone have lower sensory thresholds in the rectum compared to healthy subjects, whereas those with abdominal bloating and distention have normal or slightly higher sensory thresholds [21]. On the other hand, it has been reported that increase in abdominal girth in a day directly correlated with orocecal and colonic transit times, and inversely with stool consistency [22]. Therefore, abdominal bloating alone may be more reflection of visceral hypersensitivity, whereas abdominal bloating with distension may be more of a peripheral physiological problem.

In our subjects with IBS-C, the degree of anxiety in their daily lives was associated with severity of abdominal pain, discomfort and bloating, but not with frequency of bowel movement. It has been demonstrated that IBS patients feel more stress which may exaggerate IBS symptoms such as abdominal pain compared to healthy subjects [5]. In patients with IBS, psychological or physiological stimulus (i.e., stress) alters both visceral perception (mostly, hypersensitivity) [23-25] and colonic motility (mostly, hypercontractility even in IBS-C) 
Table 3 Associations between the degree of anxiety and GI symptoms in subjects with IBS-C

\begin{tabular}{|c|c|c|c|c|c|}
\hline Gl symptoms/Degree of anxiety & None & Sometimes & Often & Always & Kendall's \\
\hline Abdominal discomfort & & & & & $0.09^{* *}$ \\
\hline No $(n=271)$ & 76 & 153 & 34 & 8 & \\
\hline Yes $(n=488,64.3 \%)$ & 100 & 287 & 77 & 24 & \\
\hline Abdominal pain & & & & & $0.11^{* *}$ \\
\hline No $(n=538)$ & 132 & 323 & 70 & 13 & \\
\hline Yes $(n=211,29.1 \%)$ & 44 & 117 & 41 & 19 & \\
\hline Abdominal bloating & & & & & $0.08^{*}$ \\
\hline No $(n=151)$ & 42 & 91 & 13 & 5 & \\
\hline Yes $(n=608,80.1 \%)$ & 134 & 349 & 98 & 27 & \\
\hline Abdominal distention & & & & & $0.11^{* *}$ \\
\hline No $(n=368)$ & 94 & 224 & 39 & 11 & \\
\hline Yes $(n=391,51.5 \%)$ & 82 & 216 & 72 & 21 & \\
\hline Sensation of excessive gas & & & & & $0.11^{* *}$ \\
\hline No $(n=218)$ & 65 & 122 & 25 & 6 & \\
\hline Yes $(n=541,71.3 \%)$ & 111 & 318 & 86 & 26 & \\
\hline
\end{tabular}

Tightness in the abdomen

$$
\begin{aligned}
& \text { No }(n=408) \\
& \text { Yes }(n=351,46.2 \%)
\end{aligned}
$$

Abdominal fullness

$$
\begin{aligned}
& \text { No }(n=636) \\
& \text { Yes }(n=123,16.2 \%)
\end{aligned}
$$

Borborygmus

$$
\begin{aligned}
& \text { No }(n=626) \\
& \text { Yes }(n=133,17.5 \%)
\end{aligned}
$$

Increase in passing of gas

$$
\begin{aligned}
& \text { No }(n=369) \\
& \text { Yes }(n=390,51.4 \%)
\end{aligned}
$$

Decrease in passing of gas

$\begin{array}{ll}52 & 11 \\ 59 & 21\end{array}$

$$
\begin{aligned}
& \text { No }(n=736) \\
& \text { Yes }(n=23,3.0 \%)
\end{aligned}
$$

Incomplete evacuation

$$
\begin{aligned}
& \text { No }(n=326) \\
& \text { Yes }(n=433,57.0 \%)
\end{aligned}
$$

Urgency

$$
\begin{aligned}
& \text { No }(n=673) \\
& \text { Yes }(n=86,11.3 \%)
\end{aligned}
$$

Sensation of anorectal obstruction/blockage

$$
\begin{aligned}
& \text { No }(n=348) \\
& \text { Yes }(n=411,54.2 \%)
\end{aligned}
$$

Frequency of bowel habit in a week

$\begin{array}{ll}41 & 15 \\ 70 & 17 \\ & \\ 95 & 25 \\ 16 & 7\end{array}$

$$
\begin{aligned}
& >1 \text { time }(n=15) \\
& 1 \text { time }(n=60) \\
& 2 \text { times }(n=156)
\end{aligned}
$$$$
3
$$

$\begin{array}{ll}3 & 1 \\ 12 & 3 \\ 19 & 6\end{array}$


Table 3 Associations between the degree of anxiety and Gl symptoms in subjects with IBS-C (Continued)

\begin{tabular}{|c|c|c|c|c|}
\hline 3 times $(n=152)$ & 40 & 78 & 25 & 9 \\
\hline 4 times $(n=85)$ & 22 & 49 & 11 & 3 \\
\hline 5 times $(n=79)$ & 17 & 48 & 11 & 3 \\
\hline 6 times $(n=52)$ & 12 & 31 & 7 & 2 \\
\hline 7 times $(n=111)$ & 26 & 61 & 20 & 4 \\
\hline 8 times or more $(n=49)$ & 13 & 32 & 3 & 1 \\
\hline
\end{tabular}

${ }^{*} p<0.05,{ }^{* *} p<0.01$, the Kendall's $\mathrm{t}-\mathrm{b}$

$[26,27]$. However, it has been reported that only $11.5 \%$ of patients with IBS-C showed delayed colonic transit [11]. In addition, no relationship has been detected between stress factors and colonic transit in IBS patients [28]. These findings suggest that lower frequency of bowel movement in IBS-C may not always reflect inhibition of bowel movement by stress.

IBS patients often relate their symptoms to the intake of certain foods. IBS symptoms such as abdominal pain and bloating occur or are exacerbated postprandially in approximately two-thirds of patients $[3,4]$. We have previously reported that female subjects with IBS had more irregular meals and skipped meals more frequently compared to non-IBS subjects in nursing and medical school students [29]. Furthermore, IBS patients showed an exaggerated sensory component of the gastrocolonic response, expressed as lowered colonic perception thresholds and increased viscerosomatic referral area for abdominal pain after duodenal lipid infusion [30]. On the other hand, an intestinal transit study using scintigraphy revealed that IBS-C patients showed normal ileocolonic transit but somewhat delayed colonic transit in response to meal ingestion [31]. We have also demonstrated that meal ingestion did not induce altered colonic motility response in patients with IBS-C [27]. Therefore, exaggerated abdominal boating in IBS-C subjects after the meals in this study may be due to increased visceral perception, increased gut contractions and impaired propulsive movement in response to the nutritions.

A limitation of our study was to use the Internetbased survey. Subjects who were interested in own health might be more likely to participate in this survey. In the present study, 30,000 samples were collected from the large monitor panel throughout Japan and set same numbers of sex and several aged group flames. Therefore, we believe ascertainment bias is unlikely because the prevalence of overall IBS and IBS-C using the Rome III diagnostic criteria was similar to what has been reported previously for Japan $[32,33]$ or the other countries [34, 35]. Another limitation was that we did not investigate whether the presence of an organic GI disease and/or the other comorbid disease. It has been reported that IBS patients have more somatic/psychiatric comorbidities which may affect their daily lives compared to non-IBS subjects [36].

To summarize, a large population-based Internet survey has shown that a number of similarities between the Western countries and Japan, including a similar prevalence of IBS-C and a similar frequency of abdominal bloating in subjects with IBS-C. We have also shown

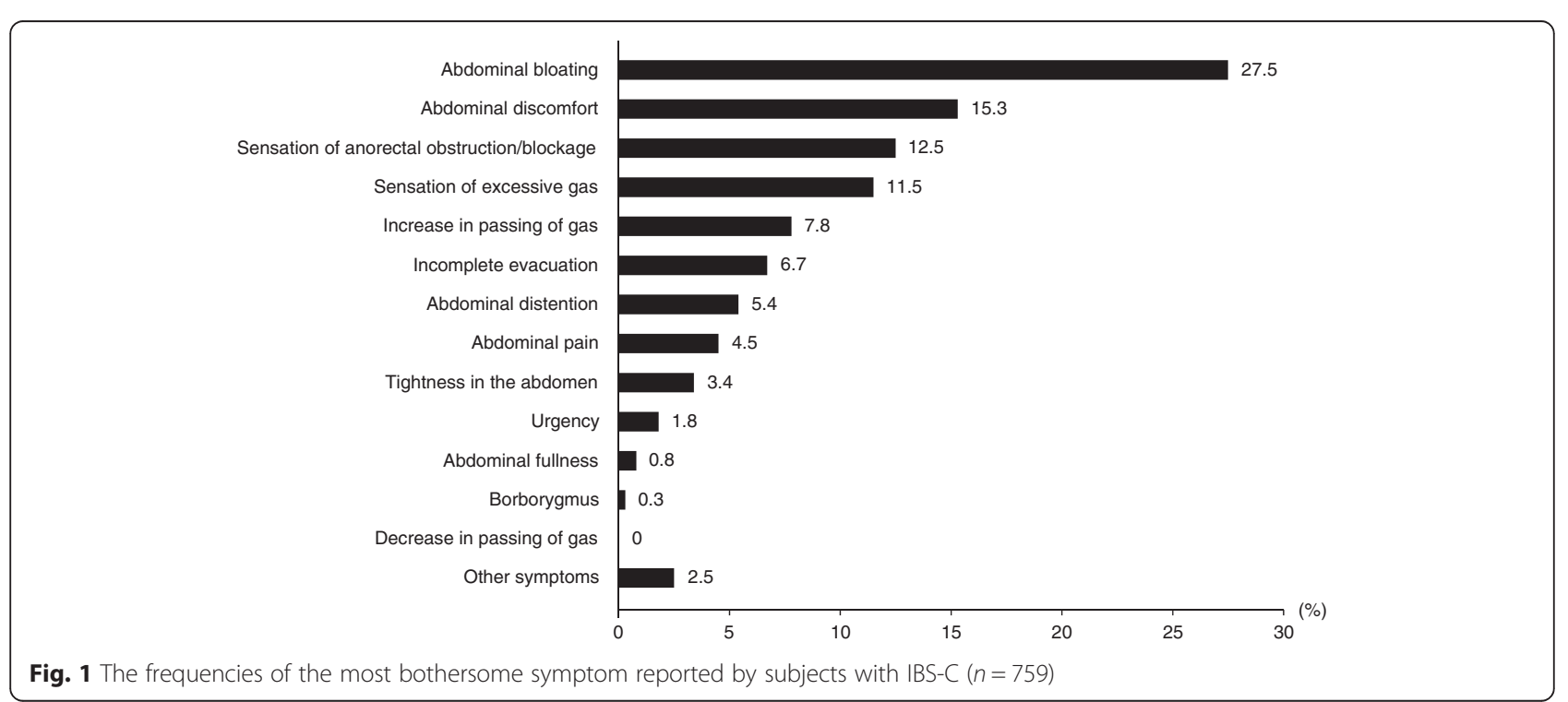


Table 4 Occurrence situations of the 'most bothersome' symptom in subjects with IBS-C

\begin{tabular}{|c|c|c|c|c|c|c|c|c|}
\hline Situations/Symptoms & $\begin{array}{l}\text { Abdominal } \\
\text { bloating } \\
(n=209)\end{array}$ & $\begin{array}{l}\text { Abdominal } \\
\text { discomfort } \\
(n=116)\end{array}$ & $\begin{array}{l}\text { Sensation of anorectal } \\
\text { obstruction/blockage } \\
(n=95)\end{array}$ & $\begin{array}{l}\text { Sensation of } \\
\text { excessive gas } \\
(n=87)\end{array}$ & $\begin{array}{l}\text { Increase in } \\
\text { passing of gas } \\
(n=59)\end{array}$ & $\begin{array}{l}\text { Incomplete } \\
\text { evacuation } \\
(n=51)\end{array}$ & $\begin{array}{l}\text { Abdominal } \\
\text { distention } \\
(n=41)\end{array}$ & $\begin{array}{l}\text { Abdominal } \\
\text { pain } \\
(n=34)\end{array}$ \\
\hline $\begin{array}{l}\text { On the way to work/school } \\
\text { by bus or train }\end{array}$ & 18.2 & 21.6 & 4.2 & 23.0 & 35.6 & 9.8 & 14.6 & 5.9 \\
\hline At work/school & 29.2 & 25.9 & 11.6 & 43.7 & 45.8 & 17.6 & 31.7 & 29.4 \\
\hline $\begin{array}{l}\text { During a conference } \\
\text { presentation/an exam }\end{array}$ & 5.7 & 10.3 & 2.1 & 9.2 & 5.1 & 3.9 & 7.3 & 8.8 \\
\hline After drinking alcohol & 2.4 & 6.9 & 3.2 & 5.7 & 6.8 & 0 & 2.4 & 0 \\
\hline After drinking milk & 2.9 & 5.2 & 3.2 & 4.6 & 3.4 & 0 & 4.9 & 11.8 \\
\hline After a meal & 52.2 & 43.1 & 22.1 & 26.4 & 39.0 & 21.6 & 43.9 & 26.5 \\
\hline On a sightseeing trip & 24.4 & 13.8 & 20.0 & 18.4 & 11.9 & 11.8 & 14.6 & 8.8 \\
\hline On a business trip & 3.3 & 6.9 & 6.3 & 3.4 & 1.7 & 2.0 & 7.3 & 2.9 \\
\hline During time of stress & 26.8 & 31.9 & 25.3 & 28.7 & 25.4 & 27.5 & 31.7 & 29.4 \\
\hline After taking some drugs & 2.9 & 1.7 & 8.4 & 0 & 0 & 0 & 2.4 & 5.9 \\
\hline $\begin{array}{l}\text { During menstruation } \\
\text { (females only) }\end{array}$ & 11.7 & 16.2 & 8.3 & 4.6 & 12.2 & 11.4 & 3.6 & 48.0 \\
\hline
\end{tabular}

Only symptoms which at least 30 subjects reported were shown. Data were expressed as frequencies (\%) in each symptom

important similarities with the previous surveys including a similar association of severity of abdominal pain with the degree of anxiety and a similar association of occurrence/exaggeration of IBS symptoms with meal ingestion and with perceived stress. Thus, these trigger factors are considered to be generalizable even in IBS-C. In constant, a significant association of frequency of bowel movement with the degree of anxiety has failed to be observed in IBS-C subjects.

\section{Conclusions}

Our findings suggest that abdominal bloating has a great impact on the daily lives of subjects diagnosed with IBS-C. Not only bowel movement/abdominal pain but also abdominal bloating should be evaluated in patients with IBS-C.

\section{Additional files}

Additional file 1: Figure S1. Online questionnaire for the preliminary study (written in Japanese). (PDF $380 \mathrm{~kb}$ )

Additional file 2: Figure S2. Online questionnaire for the main study (written in Japanese). (PDF 1000 kb)

\section{Abbreviations}

GI, gastrointestinal; IBS, irritable bowel syndrome; IBS-C, IBS with constipation; IBS-D, IBS with diarrhea; IBS-M, mixed IBS; IBS-U, unspecified IBS; $\mathrm{QOL}$, quality of life.

\section{Acknowledgements}

The authors wish to thank Macromill, Inc. for data collection and supporting data analysis.

\section{Funding}

This study was supported by Research Grant from Astellas Pharma Inc., Tokyo, Japan.

\section{Authors' contributions}

SF: the guarantor of this paper. SF, HM, AN, MaK and HA designed the study and critically reviewed the paper; and MoK performed data analysis, interpretation of the results and drafting the paper. All authors have approved the final manuscript.

\section{Competing interests}

The authors disclose the following: Motoyori Kanazawa has no conflict of interest; Shin Fukudo and Hiroto Miwa are recipient of research grant from Astellas Pharma, Inc. unrelated to this study; and Ayako Nakagawa, Masanori Kosako and Hiraku Akiho are employees of Astellas Pharma, Inc.

\section{Author details}

'Department of Behavioral Medicine, Tohoku University Graduate School of Medicine, 2-1 Seiryo, Aoba, Sendai 980-8575, Japan. ²Division of Gastroenterology, Department of Internal Medicine, Hyogo College of Medicine, Nishinomiya, Japan. ${ }^{3}$ Japan-Asia Clinical Development 2, Astellas Pharma Inc, Tokyo, Japan.

Received: 4 April 2016 Accepted: 16 May 2016

Published online: 04 June 2016

\section{References}

1. Lovell RM, Ford AC. Global prevalence of, and risk factors for, irritable bowel syndrome: a meta-analysis. Clin Gastroenterol Hepatol. 2012;10:712-21.

2. Longstreth GF, Thompson WG, Chey WD, Houghton LA, Mearin F, Spiller RC. Functional bowel disorders. Gastroenterology. 2006;130:1480-91.

3. Monsbakken KW, Vandvik PO, Farup PG. Perceived food intolerance in subjects with irritable bowel syndrome - etiology, prevalence and consequences. Eur J Clin Nutr. 2006;60:667-72.

4. Simrén M, Mansson A, Langkilde AM, Svedlund J, Abrahamsson H, Bengtsson U, Bjornsson ES. Food-related gastrointestinal symptoms in the irritable bowel syndrome. Digestion. 2001;63:108-15.

5. Chang $L$. The role of stress on physiologic responses and clinical symptoms in irritable bowel syndrome. Gastroenterology. 2011;140:761-5.

6. Kanazawa M, Endo $Y$, Whitehead WE, Kano M, Hongo M, Fukudo S. Patients and nonconsulters with irritable bowel syndrome reporting a parental history of bowel problems have more impaired psychological distress. Dig Dis Sci. 2004:49:1046-53.

7. van Tilburg MA, Palsson OS, Whitehead WE. Which psychological factors exacerbate irritable bowel syndrome? Development of a comprehensive model. J Psychosom Res. 2013;74:486-92. 
8. Houghton LA, Lea R, Jackson N, Whorwell PJ. The menstrual cycle affects rectal sensitivity in patients with irritable bowel syndrome but not healthy volunteers. Gut. 2002;50:471-4.

9. Houghton LA, Whorwell PJ. Towards a better understanding of abdominal bloating and distension in functional gastrointestinal disorders. Neurogastroenterol Motil. 2005;17:500-11.

10. Chang L, Lee OY, Naliboff B, Schmulson M, Mayer EA. Sensation of bloating and visible abdominal distension in patients with irritable bowel syndrome. Am J Gastroenterol. 2001;96:3341-7.

11. Törnblom H, Van Oudenhove L, Sadik R, Abrahamsson H, Tack J, Simrén M. Colonic transit time and IBS symptoms: what's the link? Am J Gastroenterol. 2012;107:754-60.

12. Houghton LA, Lea R, Agrawal A, Reilly B, Whorwell PJ. Relationship of abdominal bloating to distention in irritable bowel syndrome and effect of bowel habit. Gastroenterology. 2006;131:1003-10.

13. Whitehead WE, Burnett CK, Cook 3rd EW, Taub E. Impact of irritable bowel syndrome on quality of life. Dig Dis Sci. 1996:41:2248-53.

14. Patrick DL, Drossman DA, Frederick IO, DiCesare J, Puder KL. Quality of life in persons with irritable bowel syndrome: development and validation of a new measure. Dig Dis Sci. 1998:43:400-11.

15. Kanazawa M, Drossman DA, Shinozaki M, Sagami $Y$, Endo $Y$, Palsson OS, et al. Translation and validation of a Japanese version of the irritable bowel syndrome-quality of life measure (IBS-QOL-J). Biopsychosoc Med. 2007;1:6.

16. Whitehead WE, the Validation Working Team in association with the Rome Questionnaire Committee. Development and validation of the Rome III diagnostic questionnaire. In: Drossman DA, Corazziari E, Delvaux M, editors. Rome III: the functional gastrointestinal disorders. 3rd ed. McLean: Degnon Associates; 2006. p. 835-53.

17. Kanazawa M, Nakajima S, Oshima T, Whitehead WE, Sperber AD, Palsson OS, et al. Validity and reliability of the Japanese version of the Rome III diagnostic questionnaire for irritable bowel syndrome and functional dyspepsia. J Neurogastroenterol Motil. 2015;21:537-44.

18. Lee OY, Mayer EA, Schmulson M, Chang L, Naliboff B. Gender-related differences in IBS symptoms. Am J Gastroenterol. 2001;96:2184-93.

19. Tuteja AK, Talley NJ, Joos SK, Tolman KG, Hickam DH. Abdominal bloating in employed adults: prevalence, risk factors, and association with other bowel disorders. Am J Gastroenterol. 2008;103:1241-8.

20. Francis CY, Morris J, Whorwell PJ. The irritable bowel severity scoring system: a simple method of monitoring irritable bowel syndrome and its progress. Aliment Pharmacol Ther. 1997;11:395-402.

21. Agrawal A, Houghton LA, Lea R, Morris J, Reilly B, Whorwell PJ. Bloating and distention in irritable bowel syndrome: the role of visceral sensation. Gastroenterology. 2008;134:1882-9.

22. Agrawal A, Houghton LA, Reilly B, Morris J, Whorwell PJ. Bloating and distension in irritable bowel syndrome: the role of gastrointestinal transit. Am J Gastroenterol. 2009;104:1998-2004.

23. Thoua NM, Murray CD, Winchester WJ, Roy AJ, Pitcher MC, Kamm MA, Emmanuel AV. Amitriptyline modifies the visceral hypersensitivity response to acute stress in the irritable bowel syndrome. Aliment Pharmacol Ther. 2009;29:552-60

24. Naliboff BD, Waters AM, Labus JS, Kilpatrick L, Craske MG, Chang L, et al. Increased acoustic startle responses in IBS patients during abdominal and nonabdominal threat. Psychosom Med. 2008;70:920-7.

25. Nozu T, Kudaira M, Kitamori S, Uehara A. Repetitive rectal painful distention induces rectal hypersensitivity in patients with irritable bowel syndrome. J Gastroenterol. 2006;41:217-22

26. Fukudo S, Nomura T, Muranaka M, Taguchi F. Brain-gut response to stress and cholinergic stimulation in irritable bowel syndrome. A preliminary study. J Clin Gastroenterol. 1993;17:133-41.

27. Kanazawa M, Palsson OS, Thiwan SI, Turner MJ, van Tilburg MA, Gangarosa LM, et al. Contributions of pain sensitivity and colonic motility to IBS symptom severity and predominant bowel habits. Am J Gastroenterol. 2008;103:2550-61

28. Dumitraşcu DL, Grănescu S. Colonic transit investigated by radiopaque markers in females with irritable bowel syndrome: no correlation with symptoms and chronic stress. Rom J Intern Med. 1996:34:225-31.

29. Okami Y, Kato T, Nin G, Harada K, Aoi W, Wada S, et al. Lifestyle and psychological factors related to irritable bowel syndrome in nursing and medical school students. J Gastroenterol. 2011;46:1403-10.
30. Simrén $M$, Abrahamsson $H$, Björnsson ES. An exaggerated sensory component of the gastrocolonic response in patients with irritable bowel syndrome. Gut. 2001;48:20-7.

31. Deiteren A, Camilleri M, Burton D, McKinzie S, Rao A, Zinsmeister AR. Effect of meal ingestion on ileocolonic and colonic transit in health and irritable bowel syndrome. Dig Dis Sci. 2010;55:384-91.

32. Miwa H. Prevalence of irritable bowel syndrome in Japan: Internet survey using Rome III criteria. Patient Prefer Adherence. 2008;2:143-7.

33. Kubo M, Fujiwara Y, Shiba M, Kohata Y, Yamagami H, Tanigawa T, et al. Differences between risk factors among irritable bowel syndrome subtypes in Japanese adults. Neurogastroenterol Motil. 2011;23:249-54.

34. Jung HK, Halder S, McNally M, Locke 3rd GR, Schleck CD, Zinsmeister AR, Talley NJ. Overlap of gastro-oesophageal reflux disease and irritable bowe syndrome: prevalence and risk factors in the general population. Aliment Pharmacol Ther. 2007;26:453-61.

35. Krogsgaard LR, Engsbro AL, Bytzer P. The epidemiology of irritable bowel syndrome in Denmark. A population-based survey in adults $\leq 50$ years of age. Scand J Gastroenterol. 2013;48:523-9.

36. Whitehead WE, Palsson O, Jones KR. Systematic review of the comorbidity of irritable bowel syndrome with other disorders: what are the causes and implications? Gastroenterology. 2002;122:1140-56.

\section{Submit your next manuscript to BioMed Central and we will help you at every step:}

- We accept pre-submission inquiries

- Our selector tool helps you to find the most relevant journal

- We provide round the clock customer support

- Convenient online submission

- Thorough peer review

- Inclusion in PubMed and all major indexing services

- Maximum visibility for your research

Submit your manuscript at www.biomedcentral.com/submit
) Biomed Central 